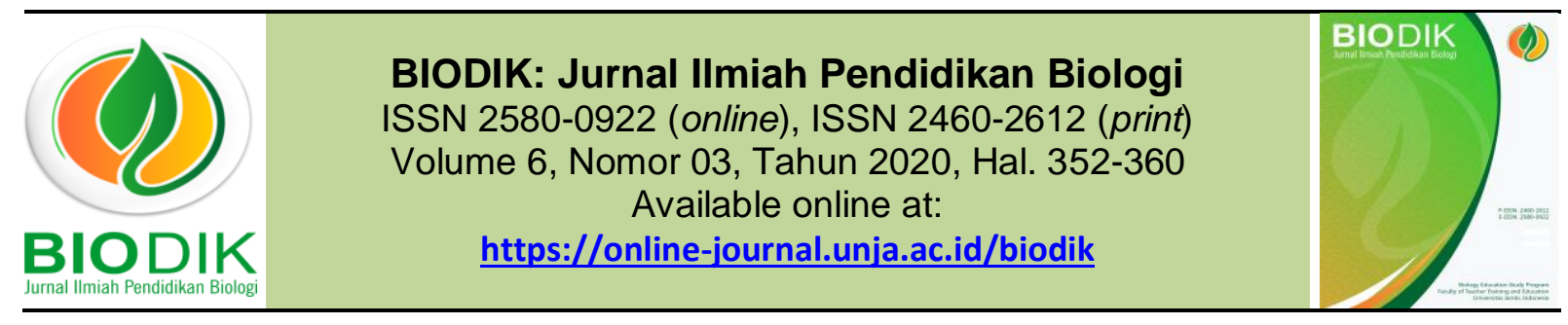

Research Article

OPEN ACCESS

\title{
Analisis Lembar Kerja Siswa Praktikum Fotosintesis Dengan Uji SACHS
}

\section{(Students Work Sheet Analysis Of Photosynthesis Practicum With SACHS Test)}

\author{
Fidya Afiyatusyifa*, Sri Anggraeni, Bambang Supriatno \\ Universitas Pendidikan Indonesia \\ Jl. Dr. Setiabudhi No.229, Cidadap, Isola, Sukasari, Kota Bandung, Jawa Barat 40154-Indonesia \\ ${ }^{*}$ Corresponding Auther: afiyatusyifa.fifadewa@gmail.com
}

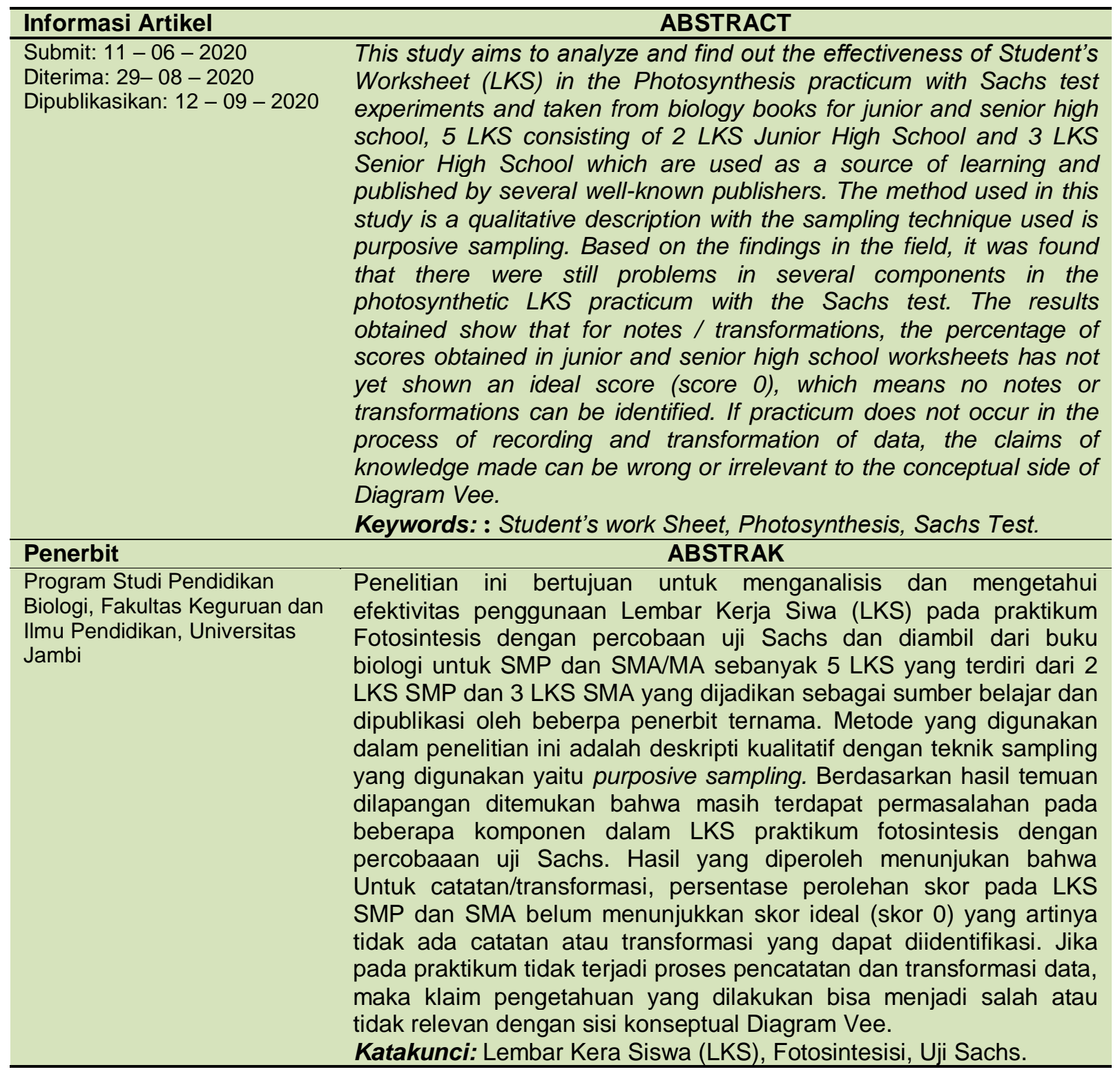


This BIODIK : Jurnal IImiah Pendidikan Biologi is licensed under a CC BY-NC-SA (Creative Commons Attribution-ShareAlike 4.0 International License)

\section{PENDAHULUAN}

Biologi merupakan salah satu kajian ilmu pengetahuan alam yang lumayan sulit dipahami oleh peserta didik, materi dalam pembelajaran Biologi terdiri dari sejumlah fakta, konsep dan prinsip. Fakta tersebut mengarahkan siswa untuk mengamati suatu objek / fenomena sehingga menghasilkan pengetahuan yang konkret. Prinsip menunjukkan bagaimana objek atau fenomena terjadi sementara konsep menunjukkan abstraksi mental dari suatu objek atau fenomena. Satu dari materi yang mengandung konsep yang dirasakan sulit dipahami oleh guru dan siswa adalah bahan fotosintesis Fotosintesis terjadi dalam kloroplas dengan bantuan energi cahaya matahari foton dan berlansung dalam 2 tahap reaksi, yaitu reaksi terang dan reaksi gelap, adapun percobaan yang membuktikan fotosintesis adalah sebagai berikut : Percobaan Engelmann, dengan bakteri thermo dan Spirogyra, Fotosintesis menghasilkan oksigen, Percobaan Ingenhouse, dengan hydrilla, Fotosintesis menghasilkan oksigen, Percobaan Sach, dengan daun yang ditutup dan terbuka, fotosintesis menghasilkan karbohidrat (Maniam, 2014).

Dalam kurikulum 2013 yang berlaku di SMA, materi fotosintesis dituntut untuk diajarkan dengan kegiatan praktikum. Materi fotosintesis merupakan salah satu materi ajar yang dianggap kompleks dan abstrak oleh siswa. Hal ini dikarenakan proses dan produk fotosintesis tidak dapat dilihat secara kasat mata. Untuk mengamati produk hasil fotosintesis dapat diobservasi salah satunya melalui uji uji Sachs (untuk mengobservasi adanya amilum).Berdasarkan Peraturan Menteri Pendidikan dan Kebudayaan (Permendikbud) Nomor 68 Tahun 2013 tentang standar kompetensi lulusan pendidikan dasar dan menengah pada Kurikulum 2013, menuntut proses pembelajaran IPA yang menitikberatkan pada aktivitas siswa. Dalam pembelajarannya, guru dituntut untuk dapat memberikan pengalaman kongkret kepada siswa melalui pengamatan atau percobaan untuk memecahkan permasalahan IPA. Agar kegiatan pembelajaran dapat memberikan pengalaman kongkret pada siswa serta berpusat pada aktivitas siswa, maka dibutuhkan kegiatan praktikum untuk menunjang keterampilan siswa (Dewi, R., Budiarti, R. S., \& Aina, M., 2017).

Kegiatan praktikum merupakan bagian terpenting dari pendidikan sains. Praktikum dapat memicu sikap ilmiah, mengembangkan keterampilan pemecahan masalah, kolaborasi dan meningkatkan pemahaman konseptual pada siswa (Okwoduba \& Okigbo, 2018) kemudian menurut Novak dan Gowin (1984) idealnya pengetahuan dapat dibentuk melalui kegiatan praktikum dengan adanya pertanyaan fokus yang relevan dengan objek, peristiwa utama, pencatatan dan transformasi, serta keterlibatan konsep, prinsip dan teori yang relevan dalam menjelaskan peristiwa yang terjadi. Merujuk pada pemaparan di atas maka untuk menunjang kegiatan praktikum, dibutuhkan sebuah pedoman/tuntunan yang dapat mengarahkan 
siswa untuk mengkonstruksi pengetahuannya berdasarkan fenomena yang muncul (Wahidah et. al, 2018). Pedoman praktikum ini dikenal dengan nama Lembar Kerja Siswa (LKS). LKS pada kegiatan praktikum fotosintesis dengan menggunakan uji Sachs, memiliki beberappa permasalahan yang muncul antara lain waktu pemetikkan daun, proses perebusan daun, pelarutan klorofil, penggunaan tabung reaksi pada proses pelarutan klorofil, tidak munculnya warna biru kehitaman pada daun yang terkena cahaya matahari, keluarnya daun dari tabung reaksi dan terbakarnya tabung reaksi pada saat pelarutan klorofil, serta pemilihan jenis daun. Selain itu pada prosedur/lamgkah kerja praktikum masih juga ditemukan ketidaksesuaian terhadap beberapa langkah praktikum yang dianggap ambigu. Temuan ini sesuai dengan penelitian Supriatno (2013) yang menyatakan bahwa prosedur praktikum meskipun rinci, beberapa di antaranya tidak terstruktur dan perintahnya membingungkan sehingga menimbulkan penafsiran ganda. Berbagai macam masalah yang muncul merupakan akibat dari tdak dilaksanakannya uji coba terhadap pedoman LKS praktikum yang digunakan.

Merujuk pada penelitian yang telah dilaksanakan oleh Supriatno (2009) menemukan hanya sebesar $24 \%$ LKS yang dapat dikerjakan dengan hasil yang sesuai prosedur dan tuntas dari segi analisis data dan penarikan kesimpulan. $76 \%$ sisanya tidak sesuai dengan prosedur. Setelah menelaah beberapa sumber LKS bersdasrkan Kurikulum 2013 dilaksanakan di SMA peneliti menemukan bahwa terdapat beberapa halyang tidak sesuai yaitu: (1) Tujuan praktikum lebih banyak menekankan aspek kognitif daripada aspek psikomotor; (2) Sebagian besar menggunakan pendekatan deduktif dengan model ekspositori; (3) Prosedur praktikum meskipun rinci, beberapa di antaranya tidak terstruktur dan perintahnya membingungkan sehingga menimbulkan penafsiran ganda; serta (4) Pemilihan materi tidak mempertimbangkan esensi, kesesuaian, kedalaman dan kompleksitasnya.Kualitas struktur LKS dinilai dengan menggunakan Diagram Vee. Diagram Vee memiliki lima komponen yang terdiri dari pertanyaan fokus (focus question), objek/peristiwa atau dikatakan (objects/events), konsep/prinsip/teori atau (concepts/principles/ theories), serta mengenai catatan/transformasi (records/transformations), dan komponen klaim pengetahuan (knowledge claim). Tiap-tiap komponen LKS tersebut dinilai kelengkapannya dengan menggunakan rubrik kelengkapan komponen LKS berdasarkan Diagram Vee. Selain itu, tiap-tiap komponen LKS juga dianalisis kualitas strukturnya dengan menggunakan rubrik penskoran.

\section{METODE PENELITIAN}

Penelitian yang dilaksanakan bertujuan untuk memberikan gambaran mengenai permasalahan LKS praktikum pada materi Fotosintesis dengan percobaan uji sachs. Pengambilan data yang dilakukan dengan menggunakan metode penelitian deskriptif karena bertujuan untuk menggambarkan fenomena-fenomena yang ditemukan. Dengan penelitian ini diharapkan dapat memberikan gambaran 
mengenai keadaan desain praktikum fotosintesis yang digunakan di Sekolah Menengah Pertam (SMP) da Sekolah Menengah Atas (SMA) di Kota Subang. Sampel yang digunakan dalam penelitian ini adalah sebanyak 5 LKPD yang terdiri dari 2 LKPD SMP dan 3 LKPD SMA yang diambil dari buku biologi untuk SMP/MTS dan SMA/MA yang dijadikan sebagai sumber belajar dan dipublikasi oleh salah satu penerbit ternama yaitu penerbit erlangga. Teknik sampling yang digunakan adalah Purposive Sampling

\section{HASIL DAN PEMBAHASAN}

Hasil temuan (Tabel 1) menunjukan masih terdapat permasalahan pada langkah kerja yang terdapat pada LKS fotosintesis SMP dan SMA. Masalah yang muncul pada saat uji langkah kerja praktikum uji Sachs, Berdasarkan hasil temuan dilapangan bahwa masih banyak terdapat permasalahan pada beberapa komponen dari LKPD praktikum fotosinyesis dengan percobaan uji Sach. Permasalahan yang muncul terdapat pada semua komponen LKS, Masalah yang paling banyak terdapat pada komponen langkah kerja dan pertanyaan fokus. Pada LKPD praktikum fotosintesis dengan percobaan Sachs yang diambi dari buku erlangga, penulis menemukan kesulitan karena pada LKS tersebut tidak dicantumkan langkah kerja merebus daun terlebih dahulu yang bertujuan untuk mematikan sel-sel yang terdapat pada daun. Kemudian pada LKS juga tidak mencantumkan cara untuk melihat butiran amilum secara jelas pada daun, langkah kerja yang dituliskan hanya bersifat mengetahui saja tidak bersifat mengidentifikasi. Alangkah lebih baik jiga ditambahkan langkah kerja untuk lebih jelas melihat butiran amilum yang terdapat pada daun, dengan langkah sebagai berikut : letakan daun di atas kaca preparat dan tutup dengan cover glass kemudian amati daun tersebut di bawah mikroskop cahaya/electron(binokuler).

Permasalahan yang terjadi pada saat uji langkah kerja ini terjadi akibat pemilihan kalimat instruksi langkah kerja yang kurang tepat sehingga makna kalimatnya membingungkan. Temuan ini sesuai dengan penelitian Supriatno (2013) yang menyatakan bahwa prosedur praktikum meskipun rinci, beberapa di antaranya tidak terstruktur dan perintahnya membingungkan sehingga menimbulkan penafsiran ganda. Selain itu, gambar ilustrasi yang ditampilkan tidak menggambarkan keadaan aslinya, serta terdapat kalimat yang menunjukkan kesalahan prosedur. Jika terjadi kesalahan prosedur, maka tujuan praktikum tidak dapat tercapai. Temuan ini sesuai dengan penelitian yang dilakukan oleh Rasyida (2010), yang menemukan bahwa $25 \%$ proses tidak mengacu pada tujuan, karena proses dari LKPD tersebut tidak dapat memunculkan fenomena yang relevan sehingga tujuan praktikum tidak tercapai. Permasalahan-permasalahan ini akan berpengaruh pada kemunculan komponen objek/event, karena instruksi langkah kerja merupakan aspek penting yang dapat menuntun siswa pada kemunculan fakta saat praktikum. Masalahmasalah tersebut terjadi akibat pemilihan LKS yang tidak melalui tahap ujicoba laboratorium. Biasanya, desain kegiatan laboratorium yang dibuat baik oleh guru 
maupun penerbit merupakan jiplakan dari desain kegiatan laboratorium yang sudah ada sebelumnya. Hal ini bersesuaian dengan pernyataan Supriatno (2009) yang menyatakan bahwa desain kegiatan laboratorium yang digunakan di sekolah banyak yang diadopsi, tanpa adaptasi dan rekonstruksi.

\section{Tabel 1. Analisi Uji Langkah Kerja LKS Praktikum Fotosintesis Percobaan Sach}

\begin{tabular}{|c|c|c|}
\hline No & Kode & Langkah Kerja \\
\hline $\mathbf{1}$ & LK1 & $\begin{array}{l}\text { Persiapkan tanaman segar yag } \\
\text { hidup di halaman/kebun } \\
\text { sekolah, misalnya singkong } \\
\text { atau tanaman lainnya yang } \\
\text { berdaun tidak tebal. }\end{array}$ \\
\hline 2 & LK2 & $\begin{array}{l}\text { Pilih daun yang akan ditutup } \\
\text { rapat dengan kertas almunium } \\
\text { foil dan diisolasi bagian } \\
\text { pinggirnya. Biarkan daun } \\
\text { tersebut tetap berada di } \\
\text { batangnya selama dua hari. }\end{array}$ \\
\hline 3 & LK3 & $\begin{array}{l}\text { Petik daun yang dututup dan } \\
\text { daun yang dibiarkan tebuka. }\end{array}$ \\
\hline 4 & LK4 & $\begin{array}{l}\text { Gunting kedua daun dengan } \\
\text { bentuk yang berbeda (misalnya } \\
\text { bentuk segitiga untuk daun } \\
\text { yang terbuka dan segi empat } \\
\text { untuk daun yang tertutup. } \\
\text { Lepaskan kertas almunium } \\
\text { foilnya. }\end{array}$ \\
\hline
\end{tabular}

$5 \quad$ LK5 Masukan kedua potongan daun ke dalam tabung reaksi yang sudah berisi alkohol $70 \%$ sebanyak $1 / 2$ dari tabung reaksi

6 LK6 Masukan tabung reaksi yang berisi daun dan alcohol ke dalam gelas beker yang berisi air setengahnya. Panaskan daun sehingga daun nampak berwarna putih pucat. Hatihati dengan menggunakan spirtus, jangan sampai membakar tubuh.

$\begin{array}{lll}7 & \text { LK7 } & \text { Ambil kedua daun yang sudah }\end{array}$ dipanaskan dan letakan di dalm cawn petri.

9.

Teteskan larutan lugol pada kedua daun, amati perubahan warnanya.

Additional langkah kerja

\section{Uraian Permasalahan}

Tidak dijelaskan megenai pemilihan daun yang akan digunakan dalam kegiatan praktikum sehingga membua siswa kebingungan.

Langkah pengisolasian kurang jelas, kemudian pada langkah kerja tidak dicantumkan waktu pengambilan daun, sehingga membuat peneliti kebingan dan pada akhirnya menutup daun pada sore hari.

tidak dicantumkan waktu pengambilan daun, sehingga membuat peneliti kebingan dan pada akhirnya menutup daun pada pagi hari.

Tidak dijelaskan maksud dari proses pengguntingan daun menjadi dua bentuk yang berbeda. Sehingga siswa tidak memiliki pengetahuan akan hal tersebut. Padahal maksud dan tujuan langkah kerja tersebut adalah dumaksudkan agar mempermudah pada proses pelarutan klorofil pada daun dengan memotong daun menjadi ukuran lebih kwcil.

Ketika proses perebusan daun dengan alkohol 70\%, tidak dijelaskan tahap demi pertahap padahal pada kenyataanya sebelum siswa melaksanakan langkah kerja tersebut terdapat beberapa langkai lainnya. Kemudian tidak dijelaskan berapa banyak alcohol dan air yang dibutuhkan.

Tabung reaksi yang berisi daun dan alkohol diletakkan miring ketika dimasukkan ke gelas kimia yang berisi air mendidih. Alkohol panas tumpah dan masuk ke dalam air mendidih, kemudian menjalar ke api bunsen sehingga pada gelas kimia, daun dan tabung reaksi terdapat api.

Pada tahap pengambilan daun tidak disebutkan alat yang dapat digunakan untuk mengambil daun pada tabung reaksi, sehingga

menimbulkan kebingungan peneliti/siswa

Tidak disebutkan berapa banyak larutan lugol yang digunakan.

\section{Perbaikan Hasil Analisis}

Persiapkan tanaman segar yag hidup di halaman/kebun sekolah, misalnya tanaman singkong atau tanaman lainnya yang berdaun tidak tebal.

Pilih daun yang akan ditutup rapat dengan kertas almunium foil dan diisolasi bagian pinggirnya. Biarkan daun tersebut tetap berada di batangnya minimal 1 hari. (Waktu penutupan daun dengan almunium foil harus dilakukan pada pagi hari ketika daun belum melakukan kegiatan fotosintesisi pukul 05.30/06.30)

Petik daun yang dututup oleh kertas almunium foil dan daun yang dibiarkan tebuka. Pemetikan dau dianjurkan pada pukul 12.00 WIB-15.00 WIB.

Lepaskan kertas almunium foil kemudian gunting kedua daun dengan bentuk yang berbeda (misalnya bentuk segitiga untuk daun yang terbuka dan segi empat untuk daun yang tertutup) hal tersebut dilakukan agar mempermudah membedakan daun yang melakukan fotosintesis dan daun yang ditutup oleh almunium foil, selain itu proses pengguntingan daun juga bertujuan untuk memudahkan memasukan daun ke dalam tabung reaksi.

Siapkan spirtus yang telah dinyalakan dengan menggunakan korek api, kaki tiga, kasa asbes, dan gelas beaker dengan ukuran $500 \mathrm{ml}$ yang telah diisi air sebanyak $250 \mathrm{ml}$, kemudian masukan potongan daun ke dalam gelas beaker secara berurutan (daun yang ditutup dengan almunium foil dan daun yang berfotosintesis). Hal tersebut dilakukan bertujuan untuk mematikan sel klorofil di dalam daun.

Masukan tabung reaksi yang berisi daun dan alcohol ke dalam gelas beker yang berisi air setengahnya. Panaskan daun sehingga daun nampak berwarna putih pucat. Hati-hati dengan menggunakan spirtus, jangan sampai membakar tubuh.

Ambil kedua daun yang sudah dipanaskan dengan menggunakn pinset dan letakan di dalm di atas cawn petr

Teteskan larutan lugol pada kedua daun, amati perubahan warnanya (3-5 tetes larutan lugol).

Untuk lebih jelas melihat butiran amilum yangterdapat pada daun, letakan daun di atas kaca preparat dan tutup dengan cover glass kemudian amati daun tersebut di bawah mikroskop cahaya/electron(binokuler). 
Hasil analisis keberadaan komponen diagram Vee pada LKS fotosintesis SMP dan SMA (Tabel 2) menunjukkan bahwa komponen yang umumnya muncul pada LKS fotosintesis SMP dan SMA yaitu pertanyaan fokus, objek/event, teori, prinsip dan konsep, serta klaim pengetahuan. Sedangkan komponen diagram Vee yang umumnya belum muncul yaitu catatan/transformasi. Hal ini disebabkan karena tidak adanya instruksi untuk mencatat dan mentransformasikan fenomena yang muncul pada saat praktikum. Hanya terdapat instruksi untuk mengamati saja. Setelah dilakukan analisis keberadaan komponen diagram Vee, dilakukan pula penskoran setiap komponen diagram Vee. Hasil temuan pada Tabel 3 menunjukkan bahwa meskipun pada LKS SMP dan SMA sudah terdapat komponen diagram Vee, namun skor yang didapatkan setiap komponennya masih rendah. Persentase perolehan skor pertanyaan fokus pada LKS fotosintesis SMP dan SMA sudah menunjukkan skor ideal (skor 3) yang artinya pertanyaan fokus yang jelas dapat diidentifikasi; termasuk konsep yang akan digunakan dan menunjukkan peristiwa utama dan objek yang menyertainya.

Tabel 2. Persentase Keberadaan Komponen Diagram Vee

\begin{tabular}{ccc}
\hline \multirow{2}{*}{ Komponen Diagram Vee } & \multicolumn{2}{c}{ Presentase (\%) } \\
\cline { 2 - 3 } & SMP & SMA \\
\hline Pertanyaan fokus & 100 & 80 \\
Objek/event & 93,75 & 100 \\
Teori, prinsip, konsep & 100 & 100 \\
Catatan/transformasi & 31,25 & 40 \\
Klaim pengetahuan & 100 & 100 \\
\hline
\end{tabular}

Untuk objek/event, persentase perolehan skor pada LKS SMP dan SMA belum menunjukkan skor ideal (skor 2) yang artinya event utama dengan objek yang menyertai dapat diidentifikasi, dan konsisten dengan pertanyaan fokus. Untuk LKS SMA, beberapa komponen objek/event SMA juga sudah menunjukkan skor ideal (skor 3) yang artinya event utama dengan objek yang menyertai dapat diidentifikasi, dan konsisten dengan pertanyaan fokus, serta menunjukkan catatan apa yang akan diambil. Untuk teori, prinsip dan konsep, persentase perolehan skor pada LKS SMP dan SMA belum menunjukkan skor ideal. Pada LKS SMP menunjukkan skor 2, yang artinya terdapat konsep dan setidaknya satu jenis prinsip (konseptual dan metodologis) atau konsep dan teori yang relevan dapat diidentifikasi. Sedangkan pada LKS SMA menunjukkan skor 3, yang artinya konsep dan dua jenis prinsip dapat diidentifikasi, atau konsep, salah satu jenis prinsip, dan teori yang relevan dapat diidentifikasi.

Ini artinya baik pada LKS SMP maupun LKS SMA pada umumnya terdapat teori, prinsip serta konsep yang dapat memberikan dasar pada siswa untuk mengkonstruk pengetahuan barunya atau sebagai dasar untuk pembelajaran lebih lanjut (Swami \& Shield, 2006, Alexander, A., Rahayu, H. M., \& Kurniawan, A. D., 2018). Teori, prinsip dan konsep ini juga akan menunjang proses pencatatan data 
serta transformasi data, karena pemahaman mengenai teori, prinsip serta konsep merupakan pengetahuan awal yang akan membantu dan mengarahkan siswa untuk lebih mudah mengorganisasi data yang didapatkan sehingga data yang didapatkan dapat menunjang pembentukan klaim pengetahuan.

Tabel 3. Persentase Keberadaan Komponen Diagram Vee

\begin{tabular}{cccc}
\hline \multirow{2}{*}{ Komponen Diagram Vee } & \multicolumn{3}{c}{ Presentase (\%) } \\
\cline { 2 - 4 } & SKOR & SMP & SMA \\
\hline Pertanyaan fokus & 0 & 0 & 20 \\
& 1 & 18 & 0 \\
& 2 & 13 & 20 \\
& 3 & 69 & 60 \\
Objek/event & 0 & 6 & 0 \\
\hline \multirow{3}{*}{ Teori, prinsip, konsep } & 1 & 0 & 20 \\
& 2 & 63 & 40 \\
& 3 & 31 & 40 \\
& 0 & 0 & 0 \\
& 1 & 0 & 0 \\
\hline \multirow{3}{*}{ Catatan/transformasi } & 2 & 81 & 40 \\
& 3 & 19 & 60 \\
& 4 & 0 & 0 \\
& 0 & 69 & 60 \\
Klaim pengetahuan & 1 & 0 & 0 \\
\hline & 2 & 31 & 40 \\
& 3 & 0 & 0 \\
& 4 & 0 & 0 \\
& 0 & 0 & 0 \\
& 1 & 6 & 0 \\
\hline
\end{tabular}

Untuk catatan/transformasi, persentase perolehan skor pada LKS SMP dan SMA belum menunjukkan skor ideal (skor 0) yang artinya tidak ada catatan atau transformasi yang dapat diidentifikasi. Jika pada praktikum tidak terjadi proses pencatatan dan transformasi data, maka klaim pengetahuan yang dilakukan bisa menjadi salah atau tidak relevan dengan sisi konseptual Diagram Vee. Menurut Supriatno (2013), jika komponen catatan dan transformasi tidak dimiliki maka DKL tersebut kurang dapat meningkatkan self awareness siswa sehingga proses metakognitifnya untuk memahami dan memaknai hasil observasi tidak terfasilitasi. Selain itu, transformasi juga dapat menggambarkan pemahaman siswa mengenai suatu praktikum karena menurut Supriatno (2013), jika siswa tidak memahami hasil observasinya, maka bentuk transformasinya akan memperlihatkan hubungan konsep yang tidak tepat, sehingga prinsip yang akan terbentuk salah.

Pernyataan ini bersesuaian dengan Novak dan Gowin (1984), yang menyatakan bahwa pencatatan data dan atau pentransformasian data ini dapat mengetahui sejauh mana siswa dapat mengkombinasikan teori, prinsip dan konsep yang mereka ketahui ke dalam rancangan catatan hasil pengamatannya. Padahal, dengan adanya perintah mencatat dan atau mentransformasikan data dapat 
membantu siswa dalam membentuk pengetahuannya dalam menjawab pertanyaan fokus sehingga kegiatan praktikum akan lebih bermakna (Solihat, 2011). Untuk klaim pengetahuan, persentase perolehan skor pada LKS SMP dan SMA belum menunjukkan skor ideal (skor 0) yang artinya pengetahuan klaim mencakup konsep yang digunakan dalam konteks yang tidak tepat atau generalisasi yang tidak konsisten dengan catatan dan transformasi. Ini terjadi karena tidak adanya kegiatan pencatatan data dan atau transformasi data yang didapatkan dalam kegiatan praktikum.

\section{KESIMPULAN}

Analisis LKS praktikum pada penelitian ini didasarkan pada Diagram Vee. Berdasarkan hasil analisis penulis pada LKS praktikum materi Fotosintesis dengan menggunakan uji sachs yang digunakan di Sekolah Menengah Pertama (SMP) dan Sekolah Menengah Atas (SMA) Berdasarkan hasil penelitian yang telah dilaksanakan ditemukan bahwa masih terdapat permasalahan pada beberapa komponen dalam LKS praktikum fotosintesis dengan percobaaan uji Sachs antara lain 1) Tujuan praktikum lebih banyak menekankan aspek kognitif daripada aspek psikomotor; (2) Sebagian besar menggunakan pendekatan deduktif dengan model ekspositori; (3) Prosedur praktikum meskipun rinci, beberapa di antaranya tidak terstruktur dan perintahnya membingungkan sehingga menimbulkan penafsiran ganda; serta (4) Pemilihan materi tidak mempertimbangkan esensi, kesesuaian, kedalaman dan kompleksitasnya. Masalah yang paling banyak terdapat pada komponen langkah kerja dan pertanyaan fokus. Pelaksanaan kegiatan praktikum Fotosintesis dengan percobaan uji Sachs masih perlu banyak mengalami perombakan pada beberapa konten yang terdapat di dalam LKS, perobakan tersebut harus berdasaran hasil analisis dan uji coba terhadap berbagai konten yang terdapat pada LKS tersebut. Kemudian pada pelaksanaannya memerlukan pengamatan yang teliti dan harus benar-benar diperhatikan, terlebih lagi saat proses pembuktian adanya karbohidrat pada daun yang melakukan fotosintesis dapat berhasil maka diperlukan ketelitian saat membungkus daun ketela pohon dengan alumunium foil agar daun betul- betul tidak mendapatkan cahaya matahari saat dibungkus.

\section{DAFTAR PUSTAKA}

Alexander, A., Rahayu, H. M., \& Kurniawan, A. D. (2018). Pengembangan Penuntun Praktikum Fotosintesis Berbasis Audio Visual Menggunakan Program Camtacia Studio di SMAN 1 Hulu Gurung. Jurnal Pendidikan Sains Indonesia (Indonesian Journal of Science Education), 6(2), 75-82. https://doi.org/10.24815/ipsi.v6i2.12075

Dewi, R., Budiarti, R. S., \& Aina, M. (2017). Pengembangan lembar kegiatan peserta didik (Ikpd) bermuatan pendidikan karakter dengan model pembelajaran guided 
inquiry pada materi bakteri bagi siswa kelas $x$ sekolah menengah atas. BIODIK, 3(1), 17-26. DOI: https://doi.org/10.22437/bio.v3i1.4878

Maniam, MBS., dan Yusa, (2014), Advanced Learning Biology 1A for Grade X Senior High School, Bandung: Grafindo.

Novak \& Gowin. (1984). Learning How to Learn. New York: Cambridge University Press.

Setiowati, T dan Furqonita, D. (2007). Biologi Interaktif. Azka Press : Jakarta.

Sagala, S. (2014). Konsep dan MaknaPembelajaran. Bandung : Alfabeta

Sudargo, F dan Asiah. (2009). "Pembelajaran Biologi berbasis Praktikum untuk Meningkatkan Kemampuan Berpikir Kritis dan KPS Siswa SMA". [online] tersedia:http://file.upi.edu/direktory/FPMIPA/jur_PEND_BIOLOGI?19510706197 8032_FRANSISKA_SUDARGO/ARTIKEL_HK_05_FRANSISKA/ARTIKEL_HIB AH_KOMPETITIF.pdf. Diakses pada tanggal 29-03-2020.

Supriatno, B. (2009). Uji Langkah Kerja Laboratorium Sekolah. Proseding Seminar Nasional Biologi: Inovasi dan Pendidikan Biologi dalam Pengembangan Sumber Daya Manusia, 255-261.

Supriatno, B. (2013). Pengembangan Program Perkuliahan Pengembangan Praktikum Biologi Sekolah Berbasis ANCORB untuk Mengembangkan Kemampuan Merancang dan Mengembangkan Desain Kegiatan Laboratorium. Disertasi Jurusan Pendidikan Biologi FPMIPA UPI: Tidak diterbitkan.

Peraturan Menteri Pendidikan Nasional Republik Indonesia Nomor 23 Tahun 2006 tentang tentang Standar Kompetensi Lulusan (SKL) Untuk Satuan Pendidikan Dasar Dan Menengah. Jakarta: Menteri Pendidikan Nasional.Rezba, Sprague dan Fiel. Tt. Learing and Assessing Science Process Skills. lowa: Kendall / Hunt Publishing Company. 